\begin{abstract}
MEMBRANE ADAPTATION IN PHOSPHOLIPIDS AND CHOLESTEROL IN THE WIDELY DISTRIBUTED, FREEZE-TOLERANT WOOD FROG, RANA SYLVATICA
\end{abstract}

by Alice Reynolds

Maintaining proper membrane phase and fluidity is important for preserving membrane structure and function in the face of environmental stress. By altering membrane composition, organisms can adapt to changing conditions. We investigated the phospholipid and cholesterol composition of liver and brain plasma membranes of Rana sylvatica seasonally in populations from Ohio and Alaska, after thermal acclimation, and during acute freezing/thawing exposure. Cholesterol levels remained constant in all experiments except in the brain after thermal acclimation, where there was less cholesterol at lower temperature, which is a common response to increase fluidity. Accordingly, liver membranes contained less cholesterol in Alaskan than Ohioan frogs. Whereas brain phospholipid composition did not change in any experiment, liver phospholipids changed in all but the freeze/thaw experiment. Predictably, phosphatidylethanolamine increased with lower acclimation temperature. From summer to winter, Ohioan frogs decreased phosphatidylcholine and increased sphingomyelin, while Alaskan frogs decreased phosphatidylserine, indicating different strategies for membrane adaptation. 


\title{
MEMBRANE ADAPTATION IN PHOSPHOLIPIDS AND CHOLESTEROL IN THE WIDELY DISTRIBUTED, FREEZE-TOLERANT WOOD FROG, RANA SYLVATICA
}

\author{
A Thesis \\ Submitted to the \\ Faculty of Miami University \\ in partial fulfillment of \\ the requirements for the degree of \\ Master of Science \\ Department of Zoology \\ by \\ Alice M. Reynolds \\ Miami University \\ Oxford, Ohio \\ 2013 \\ Advisor: Dr. Richard E. Lee, Jr. \\ Co-advisor: Dr. Jon P. Costanzo \\ Reader: Dr. Andor J. Kiss
}




\section{TABLE OF CONTENTS}

List of Tables

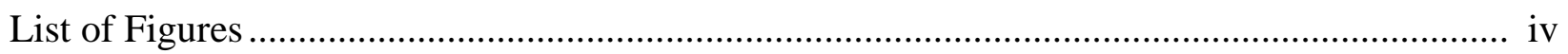

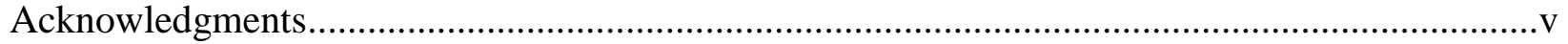

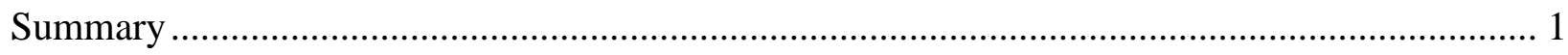

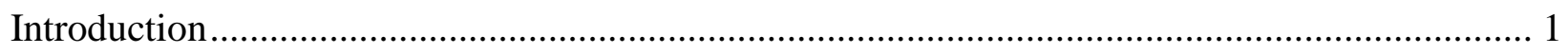

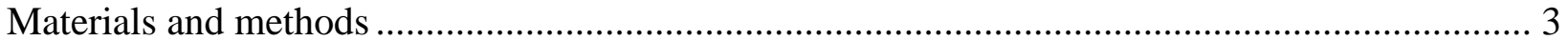

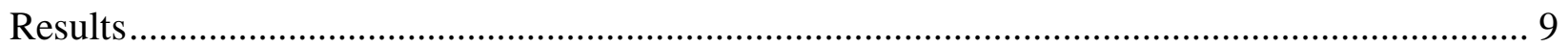

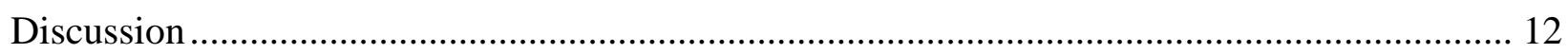

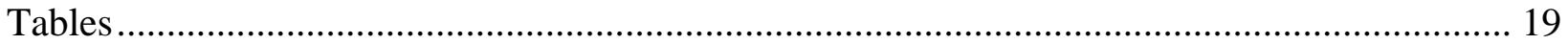

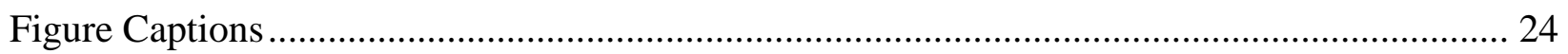

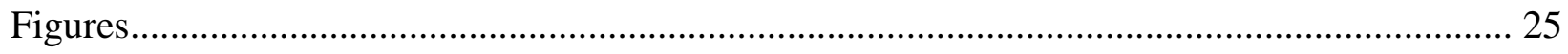

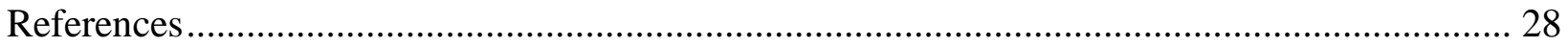




\section{LIST OF TABLES}

Table 1 Seasonal variation in plasma membrane phospholipid classes and cholesterol in liver and brain tissue of Rana sylvatica from Ohio 19

Table 2 Seasonal variation in plasma membrane phospholipid classes and cholesterol in liver and brain tissue of $R$. sylvatica from Alaska .............................................................. 21

Table 3 Phospholipid classes and cholesterol in liver and brain tissue of winter-acclimatized Ohioan $R$. sylvatica acclimated to different temperatures

Table 4 Phospholipid classes and cholesterol in liver and brain tissue of winter-acclimatized unfrozen, frozen $48 \mathrm{~h}$, and frozen $48 \mathrm{~h}$ and subsequently thawed $5 \mathrm{~d} R$. sylvatica from Ohio 


\section{LIST OF FIGURES}

Figure 1 Climatic variability as represented by the monthly average maximum and minimum air temperatures at locales near the source of the Ohioan and Alaskan frogs used in the

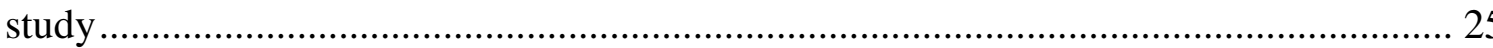

Figure 2 Variation in lipid composition of liver membranes from Ohioan and Alaskan frogs

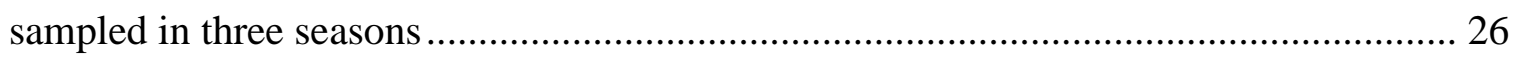

Figure 3 Variation in lipid ratios within liver membranes from Ohioan and Alaskan frogs

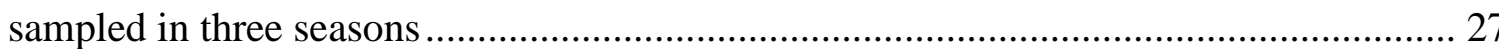




\section{ACKNOWLEDGEMENTS}

I would first like to thank Dr. Jon Costanzo for his close mentoring with this thesis and Dr.

Richard Lee and Dr. Andor Kiss for their insights and service on my committee. I also would like to thank Clara do Amaral and Andrew Rosendale for their assistance with animal collection and handling and Dr. Jason Williams for critically reading the manuscript. Finally, I thank my lab mates, family, and friends, especially my fiancé Nick Levis, for their unwavering support. Funding was provided by the National Science Foundation (IOS 1022788 to J.P.C). 


\section{SUMMARY}

Maintaining proper membrane phase and fluidity is important for preserving membrane structure and function, and by altering membrane lipid composition many organisms can adapt to changing environmental conditions. We compared the phospholipid and cholesterol composition of liver and brain plasma membranes in the freeze-tolerant wood frog, Rana sylvatica, from southern Ohio and Interior Alaska during summer, fall, and winter. We also compared membranes from winter-acclimatized frogs from Ohio that were either acclimated to 0,4 , or 10 ${ }^{\circ} \mathrm{C}$, or frozen to $-2.5{ }^{\circ} \mathrm{C}$ and sampled before or after thawing. Lipids were extracted from isolated membranes, separated by one-dimensional thin layer chromatography, and analyzed via densitometry. Liver membranes underwent seasonal changes in phospholipid composition and lipid ratios, including a winter increase in phosphatidylethanolamine, which serves to increase fluidity. However, whereas Ohioan frogs decreased phosphatidylcholine and increased sphingomyelin, Alaskan frogs only decreased phosphatidylserine, indicating that these phenotypes use different adaptive strategies to meet the functional needs of their membranes. Liver membranes showed no seasonal variation in cholesterol abundance, though membranes from Alaskan frogs contained relatively less cholesterol, consistent with the need for greater fluidity in a colder environment. No lipid changed seasonally in brain membranes in either population. In the thermal acclimation experiment, cold exposure induced an increase in phosphatidylethanolamine in liver membranes and a decrease in cholesterol in brain membranes. No changes occurred during freezing and thawing in membranes from either organ. Wood frogs use tissue-specific membrane adaptation of phospholipids and cholesterol to respond to changing environmental factors, particularly temperature, though not with freezing.

\section{INTRODUCTION}

The plasma membrane is a selective, semi-permeable barrier of the cell, essential for maintaining differing external and internal milieus. Membranes exist as a fluid bilayer in lamellar form and are composed of numerous lipid species, both polar and neutral, and proteins. For optimal function, membranes exhibit a liquid-crystalline phase, which preserves the overall membrane 
structure while also allowing membrane components appropriate freedom of motion. Variation in environmental factors, such as temperature, hydration, pressure, salinity, and $\mathrm{pH}$, can severely challenge cell membranes by inducing them to transition to other phases and thus lose their ability to function properly, resulting in the death of cells (Beney and Gervais 2001; Levitt 1980; Quinn 1985).

Hypothermic injury in a host of taxonomically-diverse, ectothermic organisms can be attributed to membrane damage resulting from thermotropic changes in constituent lipids and transition from the liquid-crystalline phase to the (lethal) gel phase (Drobnis et al. 1993; Quinn 1985). Consequently, seasonal or chilling induction of cold hardiness is commonly associated with compensatory changes in membranes that serve to increase molecular disorder and motion (i.e., fluidity) through a process termed homeoviscous adaptation, and to lower the phase transition temperature through a process termed homeophasic adaptation (Hazel 1989). Similarly, exposure to higher temperatures can also induce alterations in membrane composition that serve to maintain proper fluidity, phase, and structure. During thermal acclimation, the compensatory changes in membranes commonly include acyl-chain restructuring, adjusting phospholipid fatty acid and/or head group composition, and altering the proportions of cholesterol $(\mathrm{CH})$ and protein. To avoid cold injury and promote winter survival, it is critical that membranes adapt to low temperature (Finegold 1996).

Membrane adaptation to environmental change has been investigated in numerous ectotherms (Hazel 1995), albeit not in many amphibians, which is surprising given their excellent adaptability to a wide range of temperatures and other environmental conditions, nor in freeze-tolerant vertebrates. Owing to its high dispersal ability, broad geographic range, and extreme northern distribution (Martof and Humphries 1959), the wood frog, Rana sylvatica, is a singularly useful species in such studies. Wood frogs range from the Appalachian Mountains in the southern United States to Canada and Alaska, where they are present even within the Arctic Circle. The species is therefore adapted to temperatures that vary seasonally as well as geographically (Fig. 1). Additionally, throughout its range, the wood frog overwinters on the forest floor under a modest layer of duff and can survive the freezing of up to $65-70 \%$ of its body water (Costanzo and Lee 2013). Recently, it was reported that wood frogs from a subarctic population can survive exposure to temperatures at least as low as $-16^{\circ} \mathrm{C}$, whereas conspecifics from a more temperate population tolerate freezing at body temperatures only to -3 to $-6{ }^{\circ} \mathrm{C}$ 
(Costanzo et al. 2013). The physiological and molecular mechanisms underlying this variability are incompletely understood, but possibly include membrane adaptation to low temperature and freezing/thawing stresses, as cells remain metabolically active with the onset of subzero temperatures, upregulating numerous genes and proteins that are important for freeze-survival (reviewed in Storey and Storey 2013). Comparative studies of wood frog populations may prove highly informative because the fundamental adaptations of freeze tolerance in this species are reasonably well known (Costanzo and Lee 2013).

Given that maintenance of the liquid-crystalline membrane structure is essential to life in extremely cold environments (Finegold 1996), membrane adaptation may be an important component for winter survival in amphibians, as it is for invertebrates (Hazel 1988; Koštál 2010). Investigating membrane adaptation in a freeze-tolerant species, such as the wood frog, affords an opportunity to examine simultaneous effects of temperature and freeze-induced desiccation and osmotic imbalance during freezing and thawing, as well as critical alterations occurring during seasonal cold hardening that may enhance winter survival. Toward that end, we examined membrane adaptation to seasonal change in wood frogs from northern and southern populations, and also to thermal acclimation and experimental freezing and thawing. Using thin layer chromatography (TLC), we examined the composition of phospholipid classes and $\mathrm{CH}$ in plasma membranes from liver, the main metabolic organ of vertebrates, and from brain, as it is particularly susceptible to cryoinjury (Collins et al. 1997; Muir et al. 2010). Although in this initial project we did not evaluate acyl chain composition or membrane fluidity, the observed dynamics in phospholipid class and $\mathrm{CH}$ content provided important insights into the role of membrane remodeling in environmental adaptation in this extraordinary amphibian.

\section{MATERIALS AND METHODS}

Experimental animals and their use in seasonal experiment

Male $R$. sylvatica were collected from vernal pools in Adams County, Ohio, USA (38.8 ${ }^{\circ} \mathrm{N}, 83.3$ $\left.{ }^{\circ} \mathrm{W}\right)$ during late winter. They were transported to our laboratory, placed inside boxes containing damp moss, and kept in darkness at $4{ }^{\circ} \mathrm{C}$. Frogs were transferred in early April to a $48 \mathrm{~m}^{2}$ 
outdoor enclosure in a wooded area of the Miami University Ecology Research Center. The frogs were provided with a pool of water and offered crickets dusted with a vitamin supplement (ReptoCal, Tetrafauna, Blacksburg, VA, USA) 2-3 times weekly until mid to late October, when cooler weather curbed feeding. A few of these frogs were sampled in summer (July; $n=7)$ or fall (early November; $n=7$ ) as part of the seasonal study, but most were transferred in late October or early November to our laboratory and placed under conditions simulating hibernation. Some of these frogs were immediately used in a thermal acclimation experiment (see below), but the remainder were denied food and kept at $4{ }^{\circ} \mathrm{C}$ on damp moss in darkened boxes, conditions that simulated hibernation. In January, a group of these dormant frogs $(n=7)$ was taken to represent the winter sample in the seasonal study, whereas others were used in a freezing/thawing experiment (see below).

We collected male R. sylvatica from Fairbanks North Star Borough, near Fairbanks, Alaska, USA $\left(64.8^{\circ} \mathrm{N}, 147.7^{\circ} \mathrm{W}\right)$, during early August. Frogs were topically treated with tetracycline $\mathrm{HCl}$, placed in plastic cups containing moist paper towel, and shipped under refrigeration to Miami University where they were transferred individually to a clean plastic cup containing damp paper. Several of these frogs were sampled promptly ("summer"; $n=7$ ), but most were inducted into a dormant state (winter acclimatized) by housing them in a programmable environmental chamber (I-35X, Percival, Boone, IA, USA) and exposing them to dynamic, diel cycles of temperature and full-spectrum lighting, which, based on institutional records of weather, were seasonally appropriate to their origin. At the start of this 5.5-week regimen, temperature varied daily from 17.0 to $8.0^{\circ} \mathrm{C}$ and the photophase was $16.5 \mathrm{~h}$; at its end, in mid September, temperature varied daily from 13.0 to $2.5^{\circ} \mathrm{C}$ and the photophase was $13.3 \mathrm{~h}$. Frogs were fed ad libitum with vitamin-fortified crickets, although most refused food during the first week in September and so feeding was thereafter suspended. The crickets were the same as those used to feed the Ohioan frogs in an effort to eliminate potential effects of diet on membrane lipid composition (Berner et al. 2009; Stanley-Samuelson et al. 1985). Following acclimatization, several frogs were sampled immediately ("fall"; $n=7$ ), whereas most were kept at $4{ }^{\circ} \mathrm{C}$, in darkness, for 9 weeks in simulated hibernation until sampled in mid November ("winter"; $n=7$ ). 
All frogs were collected using approved methods under appropriate permits issued by cognizant governmental agencies. Rearing and experimental protocols were approved by the Institutional Animal Care and Use Committee (IACUC) of Miami University (protocol \#812).

Thermal acclimation experiment

In early November, some of the prehibernal Ohioan frogs were divided into three treatment groups ( $n=5$ per group) and placed individually in deli cups lined with damp paper towel. They were held for $21 \mathrm{~d}$ in darkness at 0,4 , or $10{ }^{\circ} \mathrm{C}$ inside separate environmental chambers and then immediately euthanized for tissue collection.

Freezing and thawing experiment

Winter-acclimatized frogs were subjected to experimental freezing and thawing during January. A reference group $(n=7)$ was sampled directly from their containers at $4{ }^{\circ} \mathrm{C}$ at the beginning of the experiment. Following Costanzo et al. (2013), the remaining two groups ( $n=6$ per group) were frozen to $-2.5^{\circ} \mathrm{C}$. Briefly, each frog to be frozen was voided of bladder fluid via cloacal canulation and then individually placed inside a 50-ml polypropylene tube with a thermocouple probe positioned against its abdomen. The thermocouples allowed us to record body temperature at 30-s intervals on a multichannel data logger (RD3752, Omega, Stamford, CT, USA) throughout the experiment. Tubes containing the frogs were plugged with foam and cooled to $0.7^{\circ} \mathrm{C}$ inside a refrigerated bath (RTE 140, Neslab, Portsmouth, NH, USA) with ethanol. Freezing of the frogs was initiated by applying an aerosol coolant to the exterior of the tubes. We programmed the bath to cool the frogs to $-2.5^{\circ} \mathrm{C}$ over $48 \mathrm{~h}$ at a rate of $-0.0375^{\circ} \mathrm{C} \mathrm{h}^{-1}$. The frogs were removed from the bath $48 \mathrm{~h}$ after inoculation and one group was immediately euthanized to provide tissues for analysis. The remaining frogs were gently removed from their tubes and held on damp paper at $4{ }^{\circ} \mathrm{C}$, in darkness, for $5 \mathrm{~d}$ before being euthanized and sampled.

Tissue collection and plasma membrane isolation 
Working inside a cold room $\left(4^{\circ} \mathrm{C}\right)$, the frogs from each treatment group were euthanized by double pithing and dissected. The liver and brain were quickly removed and we lightly blotted the intact liver on laboratory tissue to remove surface moisture. The tissues were then immediately frozen in liquid $\mathrm{N}_{2}$ and stored at $-80{ }^{\circ} \mathrm{C}$ until used.

We isolated the plasma membranes from samples to determine their lipid composition. For the liver, we used a highly effective isolation method from Persson and Jergil (1992), utilizing two-phase affinity partitioning, which exploits the surface properties of cellular components to segregate particles in one of two polymer solutions and also employs a ligand, wheat-germ agglutinin, specific to plasma membranes. We modified the procedure by using centrifugation to remove nuclei before the first two-phase separation, which improved visualization of the phases, and, due to the small mass of our tissue samples, we scaled the protocol to $1 / 10$ its original weights. Briefly, working at $4{ }^{\circ} \mathrm{C}, \sim 100 \mathrm{mg}(103.1 \pm 0.5 \mathrm{mg}$, mean \pm SEM) of liver tissue was homogenized (985370, BioSpec Products, Bartlesville, OK, USA) at $18,000 \mathrm{rpm}$ for $25 \mathrm{~s}$ in $0.5 \mathrm{ml}$ of a $0.25 \mathrm{M}$ sucrose buffer (in $15 \mathrm{mM}$ Tris/ $\mathrm{H}_{2} \mathrm{SO}_{4}$ with $0.1 \mathrm{mM}$ PMSF). The homogenate was centrifuged (5424, Eppendorf, Hauppauge, NY, USA) at $1000 \mathrm{~g}$ for $10 \mathrm{~min}$ to pellet the nuclei. The supernatant containing the membranes of interest was incorporated into a two-phase system and then processed as described by Persson and Jergil (1992). After the last centrifugation, the resulting pellet, enriched in plasma membranes, was resuspended in $200 \mu \mathrm{l}$ of sucrose storage buffer $(0.25 \mathrm{M}$ sucrose in $5 \mathrm{mM}$ Tris/HCl, $\mathrm{pH} 8.0)$ and stored at $-20^{\circ} \mathrm{C}$.

Plasma membranes were isolated from brain tissue in a similar fashion, but with a few modifications of the protocol. We processed the entire brain from each frog, which averaged $35.8 \pm 1.5 \mathrm{mg}$, by homogenizing it in $0.5 \mathrm{ml}$ of $15 \mathrm{mM}$ Tris $/ \mathrm{H}_{2} \mathrm{SO}_{4}$ with $0.1 \mathrm{mM}$ PMSF. The homogenate was then directly added to a $1.5 \mathrm{~g}$ two-phase system without a centrifugation to remove the nuclei. We used the modified two-phase solutions and sucrose buffers described by Schindler et al. (2006) to isolate and store the plasma membranes.

We evaluated the liver and brain preparations for plasma membrane yield by determining their enrichment in protein-specific activity of alkaline phosphatase (Graham 1993), a plasma membrane-bound enzyme, relative to that in the initial tissue homogenates. We also checked the preparations for contamination with intracellular membranes by determining enrichment in activities of succinate dehydrogenase (Graham 1993), which is associated with mitochondrial 
membranes, and NADH ferricyanide reductase (Hrycay and O'Brien 1974), which is associated with endoplasmic reticulum membranes. All marker enzyme assays were colorimetric and were performed on material that had been frozen at $-20{ }^{\circ} \mathrm{C}$ for $\sim 2-3$ weeks. Protein in the membrane preparations and initial homogenates was determined according to Bradford (1976) with bovine serum albumin as the standard.

\section{Lipid extraction and thin layer chromatography}

We extracted lipids from the isolated membranes following the procedure of Berner et al. (2009), which is a variant of the Folch method that uses a solvent system of chloroform-methanol 2:1 (v/v) with $0.01 \%(\mathrm{w} / \mathrm{v})$ butylated hydroxytoluene (BHT) as an antioxidant. The phases were separated with $1 \mathrm{M} \mathrm{H}_{2} \mathrm{SO}_{4}$. The samples containing the extracted liver and brain lipids were reduced in volume by 90 and $95 \%$, respectively, by evaporating the chloroform under vacuum in a desiccator. These concentrated lipid samples were briefly stored at $-20{ }^{\circ} \mathrm{C}$ until used with TLC.

One-dimensional TLC with two developing solutions was used to separate six different classes of phospholipids and the more neutral lipid, $\mathrm{CH}$. To improve phospholipid class separation, glass-backed silica gel 60 TLC plates with $254 \mathrm{~nm}$ fluorescent indicator (20 cm x 20 cm, EMD Millipore, Billerica, MA, USA) were impregnated with $1 \mathrm{mM}$ EDTA (pH 5.5), as described by Ruiz and Ochoa (1997). Prior to their use for lipid separation, the plates were developed in chloroform-methanol-water 60:40:10 (v/v/v) for $2 \mathrm{~h}$ in the same direction as the EDTA impregnation and were activated at $110^{\circ} \mathrm{C}$ for $30 \mathrm{~min}$ (Ruiz and Ochoa 1997).

Five standard solutions were prepared, each consisting of equal amounts of phosphatidylcholine (PC), phosphatidylethanolamine (PE), sphingomyelin (SM), and $\mathrm{CH}$ (Sigma-Aldrich, St. Louis, MO, USA, or VWR, Radnor, PA, USA) at concentrations of 0.6, 0.4, $0.2,0.1$, or $0.05 \mu \mathrm{g} / \mu \mathrm{l}$ in chloroform. A non-native lipid, cholesteryl formate, was added as an internal standard to each standard solution and lipid sample at $0.4 \mu \mathrm{g} / \mu \mathrm{l}$ (Ruiz and Ochoa 1997). We spotted $10 \mu \mathrm{l}$ of each standard or sample on the plates. To separate the polar lipids, the plates were developed in chloroform-methanol-water 60:35:8 (Radin et al. 1982) until the solvent front reached halfway up the plate ( $25 \mathrm{~min})$. The plates were thoroughly dried and developed in hexanes-heptanes-diethyl ether-acetic acid 63:18.5:18.5:1 (Schmitz et al. 1984), until the solvent 
front reached $2 \mathrm{~cm}$ from the top of the plate $(\sim 45 \mathrm{~min})$, to separate the neutral lipids. Both developing solutions contained $0.01 \%$ BHT.

TLC plates were visualized by the charring method of Bitman and Wood (1982). Briefly, plates were submerged for $10 \mathrm{~s}$ in a solution of $10 \%$ cupric sulfate (w/v) in $8 \%$ phosphoric acid (v/v), dried over a hot plate just until lipid spots appeared, and then baked at $200{ }^{\circ} \mathrm{C}$ for 4 min on flat metal pans to ensure even charring. Individual lipids were identified by comparison with cochromatographed standards or results in previous reports (Ruiz and Ochoa 1997; Schuh 2002). The plates were then scanned (CanoScan 9950F, Canon, Melville, NY, USA) and analyzed via densitometry with AlphaView software (version 1.0.1.10, Alpha Innotech). Density values of the lipid samples on each plate were calibrated with the standards to eliminate variability among plates. The percentage of total phospholipids represented individually by PC, PE, SM, phosphatidylinositol (PI), phosphatidylserine (PS), and lysophosphatidylcholine (LPC) was calculated for each frog sample. Similarly, the percentage of total lipids represented by $\mathrm{CH}$ was calculated for each sample. Data were presented as mean percentages \pm SEM. The ratio of $\mathrm{CH}$ to total phospholipids (CH/PL) was computed, along with the phospholipid ratios PC/PE, PC/PI, and $\mathrm{PC} /(\mathrm{PE}+\mathrm{SM})$, as these ratios can inform about a membrane's fluidity and other properties (e.g. Fajardo et al. 2011, Hazel 1995). The PC/(PE+SM) ratio was proposed by Fajardo et al. (2011) to provide a more robust and empirically supported determination of membrane fluidity, at least in mammalian membranes.

\section{Statistical analysis}

For all experiments, the mean ratios and percentages within each experiment were analyzed by Analysis of Variance (ANOVA) followed by Bonferroni's multiple comparisons test, when appropriate. In the seasonal experiment, two-factor ANOVA (season $\times$ population) was used to test for differences between the populations, and the means within each season were distinguished with Bonferroni's comparisons test. All percentage data and any ratio data that were non-normally distributed were arcsine-transformed before use in statistical analyses.

Datasets were tested to ensure they met parametric assumptions of normality through graphical representation and the Shapiro-Wilk test, as well as homoscedasticity with the Brown-Forsythe Levene-type test. In four cases, where these conditions were not met, data were analyzed using 
the nonparametric Kruskal-Wallis test. Analyses were performed using R (version 2.15.1) with significance set at $\alpha=0.05$.

\section{RESULTS}

Membrane extractions for both liver and brain were highly enriched with plasma membranes as determined by a 10-fold increase in alkaline phosphatase activity in membrane pellets over tissue homogenates. The membranes contained minimal contamination from mitochondrial and endoplasmic reticulum membranes, as we found only a 3-fold increase in succinate dehydrogenase activity (from mitochondria) and a 2-fold increase in NADH ferricyanide reductase activity (from endoplasmic reticulum).

The proportions of lipid classes found in liver membranes were similar to previously reported values for a closely related species, R. pipiens (Rouser et al. 1969). Our values for brain membranes were also similar to published values for neural tissue of an unnamed anuran (Siakotos et al. 1969) and brain microsomes of R. temporaria (Cuzner et al. 1965).

\section{Seasonal membrane adaptation}

Phospholipid composition of liver membranes in Ohioan frogs changed seasonally in half of the classes investigated (Table 1). These changes occurred between summer and fall, with fall levels persisting in winter, in most cases. The proportion of PC substantially decreased from $43.3 \pm 0.6$ $\%$ in summer to $37.7 \pm 0.7 \%$ in fall, while PE increased markedly during that period. PI was nominally lower in summer $(8.1 \pm 0.9 \%)$ than winter $(10.2 \pm 0.2 \%)$, although differences in these means were not significant $(P=0.091)$. SM moderately increased in relative abundance from summer to fall, but then decreased in winter to a percentage that was not statistically different from the summer value. All three phospholipid ratios, $\mathrm{PC} / \mathrm{PE}, \mathrm{PC} / \mathrm{PI}$, and $\mathrm{PC} /(\mathrm{PE}+\mathrm{SM})$, were significantly higher in summer than fall and winter (Table 1), suggesting that the membranes increased their fluidizing constituents to reduce the rigidifying effect of lower fall and winter temperatures on membrane fluidity. The proportion of $\mathrm{CH}$ to total lipids and the $\mathrm{CH} / \mathrm{PL}$ ratio did not change in liver membranes. 
Unlike the case with liver, there was no seasonal change in the lipids of brain membranes from Ohioan frogs (Table 1). We found no variation in phospholipid composition or phospholipid ratios. Neither did we find any change in $\mathrm{CH}$ content. The ratio $\mathrm{CH} / \mathrm{PL}$ was nominally lower in winter $(0.34 \pm 0.02)$ than in summer $(0.37 \pm 0.02)$ and fall $(0.43 \pm 0.03)$, although these differences were not quite significant $(P=0.073)$.

Alaskan frogs exhibited marked seasonal changes in the phospholipid composition of liver membranes (Table 2). As with Ohioan frogs, the relative abundance of PE significantly increased from summer to winter. PC increased slightly (albeit not quite significantly; $P=0.069$ ) from summer and fall to winter, which was in the opposite direction from Ohioan frogs. PS, which did not change seasonally in Ohioan frogs, markedly decreased from summer to winter in Alaskan frogs (Table 2). None of the phospholipid ratios differed among seasons, and neither did $\mathrm{CH}$ content or the ratio $\mathrm{CH} / \mathrm{PL}$.

In Alaskan frogs, we found no seasonal variation in the lipids of brain membranes (Table 2). All the phospholipid classes and, consequently, phospholipid ratios, remained static, as did $\mathrm{CH}$ content and $\mathrm{CH} / \mathrm{PL}$.

Lipid composition of liver membranes differed markedly between Ohioan and Alaskan frogs, as the population term and/or interaction (season $\times$ population) term of the two-factor ANOVAs were significant $(P<0.020$, all cases) for all lipids except PE and LPC. Patterns of variation and distinctions between means within each season are depicted in Fig. 2. The percentage of PC in membranes from Ohioan frogs was higher in summer, but lower in winter, as compared to Alaskan frogs. Conversely, the percentages of both PS and SM were comparatively higher in summer in Alaskan frogs. The relative abundance of PI was similar between the populations in summer, but in winter was substantially higher in Ohioan versus Alaskan frogs. The populations differed markedly in $\mathrm{CH}$ content, with higher amounts found in Ohioan frogs: the percentage of $\mathrm{CH}$ in liver membranes averaged over all seasons was $16.0 \pm 0.6$ $\%$ for Ohioan frogs and $13.4 \pm 0.8 \%$ for Alaskan frogs.

Significant population and/or interaction terms $(P<0.015$, all cases) of the two-factor ANOVAs indicated that all lipid ratios differed between Ohioan and Alaskan frogs (Fig. 3). Generally, higher ratios, which are indicative of lower membrane fluidity at a given temperature and a higher temperature of transition to the inverted hexagonal phase, were found in Ohioan 
frogs in summer and in Alaskan frogs in winter. As with $\mathrm{CH}$ content, $\mathrm{CH} / \mathrm{PL}$ was higher in Ohioan frogs, regardless of season.

Relative abundances of all phospholipid classes, as well as $\mathrm{CH}$ content, in membranes prepared from brain tissue were similar $(P>0.05$, all cases) between Ohioan and Alaskan frogs. Accordingly, we found no populational variation in any of the lipid ratios $(P>0.05$, all cases $)$.

\section{Membrane adaptation in thermal acclimation}

There was little change in lipid composition of liver membranes during the $21-\mathrm{d}$ period of thermal acclimation (Table 3). However, compared to membranes from frogs acclimated to 10 ${ }^{\circ} \mathrm{C}$, PE showed a higher relative abundance in membranes collected from frogs acclimated to either 4 or $0{ }^{\circ} \mathrm{C}$. No other phospholipid class varied among the groups. With decreasing temperature there was a reduction in $\mathrm{PC} / \mathrm{PE}$, and a nearly significant $(P=0.056)$ decrease in $\mathrm{PC} /(\mathrm{PE}+\mathrm{SM})$, implying that increased levels of fluidizing constituents help to maintain appropriate membrane viscosity in the cold. However, the other lipid ratios, as well as $\mathrm{CH}$ content, remained unchanged.

Thermal acclimation was associated with relatively little change in the lipid composition of brain membranes (Table 3). No phospholipid classes or phospholipid ratios varied among groups. On the other hand, $\mathrm{CH}$ content diminished with acclimation temperature, being substantially lower in frogs acclimated at $0{ }^{\circ} \mathrm{C}(23.1 \pm 1.3 \%)$ than in those acclimated at $10{ }^{\circ} \mathrm{C}$ $(28.6 \pm 1.6 \%)$. Correspondingly, $\mathrm{CH} / \mathrm{PL}$ also decreased with temperature.

\section{Membrane adaptation in freezing/thawing}

We found no changes in lipid composition or lipid ratios in membranes from liver or brain during freezing and thawing exposure (Table 4). There was a nominal decrease in $\mathrm{CH}$ content and $\mathrm{CH} / \mathrm{PL}$ after $48 \mathrm{~h}$ of freezing, followed by a return to higher values in 5-d-thawed frogs, although these changes were not statistically significant $(P=0.095$ and 0.086 , respectively). 


\section{DISCUSSION}

The primary aim of this project was to gain insights into the cellular adaptations to environmental and physiological change in the wood frog by examining the responses of select constituents of the plasma membranes from two organs with distinct functions. Plasma membranes are complex structures composed of several classes of phospholipids, sterols, a host of proteins, and diverse combinations of fatty acyl chains, and all of these components, together with certain intra- and extracellular solutes, dynamically interact to influence membrane behavior. Therefore, one must be cognizant of this complexity when interpreting our results, which only addressed dynamics of phospholipid class and $\mathrm{CH}$. This limitation notwithstanding, our findings not only provide firm evidence that adjustments in membrane composition are an important adaptive response in this species, but also indicate that more descriptive and mechanistic studies, including those that directly explore changes in membrane fluidity and phase, will be especially instructive.

Seasonal membrane adaptation

\section{Responses of liver membranes from southern frogs}

Liver membranes from Ohioan frogs changed seasonally in several ways that apparently regulate certain membrane properties. Consistent with previous studies of ectotherms (Hazel 1988), PC decreased from summer levels, as the frogs presumably experienced lower temperatures in the fall and winter (Fig. 1). This is a beneficial change that reduces membrane order because, with its cylindrical shape, $\mathrm{PC}$ is a membrane-ordering lipid that allows close packing of lipids. Contrary to PC, PE is a disordering lipid because its conical shape helps prevent close packing of

lipids, allowing for more movement and, hence, fluidity in the membrane. It also tends to contain more unsaturated carbon chains, which further fluidizes the membrane. Accordingly, like the case with our Ohioan wood frogs, ectotherms commonly exhibit an increase in the proportion of PE in response to a decrease in seasonal or acclimation temperature (Hazel 1995; Scapin et al. 1990; Tomčala et al. 2006). As a conical lipid, PE prefers to form an inverted hexagonal phase instead of a lamellar phase and is found largely in the inner leaflet of the membrane; therefore, it 
has been postulated that PE plays a key role in membrane fusion, exocytosis, and endocytosis (Boggs et al. 1981; Hazel 1995). As wood frogs prepare for the challenges of winter, including the risk of freezing, increasing the proportion of PE, as we observed, could help their membranes retain their ability to import and export important biological compounds.

Unlike the case with the more abundant phospholipids, PC and PE, whose functions in membranes are better understood, the roles of the less abundant phospholipids in seasonal and thermal adaptation are equivocal. Cold acclimation of ectotherms can induce an increase in the PI content of membranes (Pruitt 1988; Wodtke 1978), a change that may help fluidize (Hazel 1995) and stabilize (Wodtke 1978) them. Similarly, we observed a pattern of increasing PI from summer to winter in Ohioan wood frogs, though the change was not statistically significant. However, we also observed an increase in SM during fall, and its maintenance at high levels in winter, which presumably has an opposing (rigidifying) effect on membrane fluidity (Fajardo et al. 2011). This seemingly untoward response suggests that the influence of SM on membrane order may be of lesser importance than its various other functions, such as conferring chemical resistance to oxidation and serving as a receptor molecule for extracellular ligands (Slotte 2013).

\section{Responses of liver membranes from northern versus southern frogs}

Wood frogs from the northern part of their range are adapted to cooler, shorter summers and colder winters than frogs from more temperate regions (Martof and Humphries 1959; Fig. 1). They presumably also have a higher metabolism at a given temperature than their southern counterparts (e.g., Bullock 1955). Therefore, we expected that membranes from Alaskan and Ohioan frogs would show distinct differences in the way they responded to a change of season. In general, we found this to be the case, as only PE showed the same pattern of change (an increase in winter) in both Alaskan and Ohioan frogs. Unexpectedly, and contrary to the case with Ohioan frogs, PC was nominally (but not quite significantly) highest in winter-acclimated Alaskan frogs. Conceivably, this could serve to increase water binding, which contributes to the exceptional freeze tolerance in this northern phenotype (Costanzo et al. 2013); indeed, of the more abundant phospholipids, PC is the strongest water binder (Jendrasiak 1996).

We also observed marked populational differences in the seasonal dynamics and relative amounts of the less abundant membrane phospholipids. Notably, in Alaskan frogs, levels of PS 
and SM were higher in summer, and PI was lower in winter, as compared to Ohioan frogs. Furthermore, unlike the case with Ohioan frogs, we found no indication that PI and SM changed seasonally in Alaskan frogs, and only in the northern phenotype was PS strongly labile, being lower in winter than in summer. The observed winter reduction in this phospholipid is consistent with a previous report that PS decreases with acclimation temperature (Zehmer and Hazel 2005). As an intermediate in the biosynthesis of PE (among other roles; Leventis and Grinstein 2010), it is possible that some of the PS in frog membranes is converted to PE as summer progresses into fall and winter. However, the reason why this change occurred in Alaskan but not Ohioan wood frogs is unclear. Presumably, the observed variation in seasonal dynamics and relative amounts of membrane phospholipids reflects the specific needs of the liver membrane imposed by distinct climatological factors.

Given that a reduction in membrane levels of $\mathrm{CH}$, which has an ordering (i.e., rigidifying) effect on membranes in the liquid-crystalline phase (Yeagle 1985), is a common response to cold acclimation in many ectotherms (e.g., Crockett 1998), we anticipated finding a lower level of $\mathrm{CH}$ in the liver membranes of frogs during the cooler seasons. However, similar to the case with $R$. esculenta (Scapin et al. 1990), we found no seasonal variation in membrane levels of $\mathrm{CH}$ in wood frogs from either population, suggesting that, at least in liver tissue, this lipid's influence on membrane order is subordinate to its other functions. On the other hand, the comparatively low levels of $\mathrm{CH}$ in membranes of Alaskan versus Ohioan frogs during all seasons probably are needed to help offset the ordering effect of the generally cooler environment to which these frogs are adapted (e.g., Hassett and Crockett 2009; Hazel 1988).

\section{Lipid ratios and liver membrane structure}

We used several lipid ratios to make inferences about membrane fluidity, the physical state of the membrane (phase), and lipid phase-transition temperatures. With homeoviscous adaptation, membrane composition is continuously adjusted to maintain a certain level of fluidity under different environmental conditions, whereas with homeophasic adaptation, membrane composition is adjusted to preserve the liquid-crystalline phase under varying environmental conditions (Hazel 1989). A transition to either the gel phase with low temperature or the inverted hexagonal phase with high temperature leads to a loss of proper membrane function or bilayer 
integrity. Because PC can remain in the liquid-crystalline phase at temperatures where lipids such as PE are in either of the two other phases (Chapman 1975; Lee 1977), a decrease in our phospholipid ratios at more extreme temperatures potentially could indicate detrimental shifts in phase-transition temperatures (e.g., lower transition temperature at high temperature and vice versa). A balance between homeoviscous and homeophasic effects of lipids must be reached, though in ectotherms, homeoviscous effects seem to be more prevalent (Hazel 1989).

In Ohioan frogs, the observed decrease of PC/PE and PC/PI from summer to fall or winter agrees with findings of previous studies (Hazel 1988; Pruitt and Lu 2008) and suggests that fluidizing components of the liver membranes are increased during the cooler seasons to maintain membrane fluidity in the face of potentially rigidifying temperatures. We reached the same conclusion with $\mathrm{PC} /(\mathrm{PE}+\mathrm{SM})$, a ratio presented by Fajardo et al. (2011) as a highly correlated indicator of membrane fluidity. However, those authors maintained that a lower value for this ratio indicates a less fluid membrane, but this interpretation regards mammals, which may respond differently to environmental stresses and/or favor homeophasic adaptation (Hazel 1988). In stark contrast to Ohioan frogs, the phospholipid ratios in liver membranes from Alaskan frogs did not change seasonally, perhaps because they experienced relatively low temperatures throughout the year (Lee 1974).

Though homeoviscous adaptation is ubiquitous among ectotherms, some evidence suggests that in wood frogs homeophasic adaptation may also be important. The particular phospholipid class composition in northern and southern phenotypes presumably ensures that the liquid-crystalline phase is preserved at the prevailing environmental temperatures experienced in their respective habitats. Although the phospholipid fatty acid and membrane protein composition also affect phase transition, our results only speak to the presumed effect of changes in lipid classes at a given temperature. In summer animals, for example, phospholipid ratios indicate that the temperature for transition to the adverse inverted hexagonal phase was higher in Ohioan versus Alaskan frogs, which corresponds with the higher prevailing summer temperatures they likely experience (Fig. 1). Similarly, during winter, the inferred lower temperature of transition to the harmful gel phase in Alaskan versus Ohioan frogs seems consistent with the much colder winters they endure (Costanzo et al. 2013).

Among ectotherms, acclimation to low temperature commonly results in reduced $\mathrm{CH}$ content of the membrane (e.g., Cuculescu et al. 1995; Hazel 1988; Sørensen 1993), consistent 
with a homeoviscous interpretation of increased fluidity with lower CH/PL. We observed a stable, low $\mathrm{CH} / \mathrm{PL}$ in the northern phenotype, which is likely an adaptation to preserve proper membrane function under perpetually cool conditions. It is important to note that, whereas lipid ratios can be used to draw inferences about membrane properties, direct measures of membrane fluidity and transition temperatures are needed to validate such inferences.

\section{Responses of brain membranes}

The liver showed more seasonal variation in lipid composition and relative abundance than brain, perhaps because it is more active metabolically and, therefore, has a greater need for adaptability (Hazel 1988; Robertson and Hazel 1996). Conceivably, the membranes of brain cells must maintain a relatively static lipid class composition to function at optimal levels. Alternatively, a role for phospholipid changes in brain membranes may be negated by their relatively high $\mathrm{CH}$ content, which may act as a tempering agent against adverse fluidity and phase changes; indeed, membranes with high $\mathrm{CH}$ content (>20\%) apparently do not exhibit gel-phase transitions (Hazel 1988; Yeagle 1985). On the other hand, given that some studies have shown that homeoviscous adaptation occurs in brain membranes (Behan-Martin et al. 1993; Cossins and Prosser 1978), it is possible that seasonal adaptation involved certain membrane components (e.g., fatty acids) that we did not investigate.

Membrane adaptation in thermal acclimation

Among ectotherms, cold acclimation is commonly associated with an increase in the membrane level of PE, a disordering lipid, and a decrease in PC, an ordering lipid, as these changes tend to increase membrane fluidity (Hazel 1988). Similarly, in cold acclimation, membranes typically show a decrease in $\mathrm{CH}$, which, accordingly, serves to increase fluidity at a given temperature (Crockett 1998). Our finding that the plasma membranes of wood frogs acclimated to cold underwent alterations that molecularly decrease the order of membrane lipids (i.e., PE increased in the liver; $\mathrm{CH}$ decreased in the brain) largely concurs with results of other studies of thermal acclimation in ectotherms (reviewed in Hazel 1995). The maintenance of membrane fluidity in

response to cold acclimation was also suggested by the observed decreases in PC/PE in liver and 
$\mathrm{CH} / \mathrm{PL}$ in brain. These alterations may offset the rigidifying effects of low temperature, enabling membranes to maintain an optimal environment promoting their structural integrity and function. Though thermal acclimation of our frogs did induce some expected changes, they were not as extensive as the changes induced by seasonal acclimatization, suggesting that temperature in combination with other abiotic factors is a more potent stimulus for membrane remodeling.

Our acclimation experiment showed that certain lipid classes differed in wood frogs acclimated to temperatures that varied by only ten degrees Celsius. Such changes are typically manifested in ectotherms exposed to larger temperature ranges $\left(15-20^{\circ} \mathrm{C}\right.$; e.g., Pruitt 1988 ; Wodtke 1978). Thus, the sensitivity of thermal response seems particularly high in wood frogs, as is expected of an eurythermal species, which typically show more membrane plasticity than stenothermal species (Cossins and Prosser 1978). Nevertheless, changes to membrane composition incur an energetic cost, so this thermal sensitivity must be balanced with other physiological needs.

\section{Membrane adaptation in freezing/thawing}

Homeoviscous adaptation in the context of winter acclimatization has been most thoroughly investigated in freeze-avoiding species. However, the membranes of freeze-tolerant species must compensate not only for the rigidifying effect of cold, but also for the stress imposed by cellular dehydration because, as ice accumulates within extracellular compartments, the removal of liquid water from the cell raises the membrane's thermotropic phase-transition temperature and promotes loss of lamellar structure (Crowe and Crowe 1986; Steponkus 1984). The wood frog is the best studied of freeze-tolerant vertebrates (Costanzo and Lee 2013) but has not been investigated with respect to membrane adaptation in response to freezing and thawing. In fact, to our knowledge the present is the first study to examine the response of membrane phospholipids to freezing and thawing in any freeze-tolerant animal.

Neither of the organs we studied underwent any detectable changes in membrane lipids with experimental freezing or thawing. Indeed, the lipid composition of membranes from both liver and brain remained remarkably static, despite being exposed to marked changes in osmoionic conditions. This finding contrasts with previous reports of plants exhibiting membrane adaptation in response to freezing (e.g., Sikorska and Kacperska-Palacz 1980; Welti et al. 2002). 
However, it is possible that the period of freezing ( $48 \mathrm{~h}$ ) used in our experiments was too brief to elicit changes in phospholipid classes in wood frogs. Although such changes reportedly can occur within hours (Carey and Hazel 1989; Welti et al. 2002; Williams and Hazel 1995), this process can take up to several days (Brooks et al. 2002; Hazel 1988) or, conceivably, even longer at the low temperatures involved in freezing. Consequently, future studies should investigate the effects of longer freeze durations. Furthermore, other membrane components, such as fatty acids, should be examined as they possibly change more rapidly than phospholipid class. It is also possible that solutes such as urea and sugars, which are known to protect membranes during osmotic stress (Costa-Balogh et al. 2006, Crowe et al. 1987) and to accumulate in wood frogs in advance of and/or during freezing (Costanzo and Lee 2013), may negate the need for membranes to undergo energetically costly lipid alterations.

\section{Summary and perspectives}

Membrane adaptation is one of the strategies wood frogs use to respond to changing environmental conditions, particularly temperature, though the adaptations seem to be tissuespecific, as seasonal changes in phospholipid composition occurred in liver, but not in brain. In contrast to Alaskan frogs, which experience a range of relatively low temperatures year round, Ohioan frogs experience moderately cold winters as well as hot summers (Fig. 1) and exposure to these higher temperatures, which may have disproportionate effects on membrane adaptation (van Dooremalen et al. 2011; Zehmer and Hazel 2005), potentially resulted in the more seasonally labile lipid composition in their liver membranes. With thermal acclimation, membranes showed responses typical of ectotherms that increase fluidity at lower temperatures; however, no changes in phospholipid class or $\mathrm{CH}$ occurred during freezing and thawing, possibly due to the limited time allowed for changes or the effects of other responses that were not studied. As membrane adaptation is not limited to phospholipids and $\mathrm{CH}$, future studies should examine other possible changes (e.g., fatty acid composition, acyl-chain restructuring, and protein content) in the wood frog and other anurans, potentially identifying phenotypic differences among populations and species that provide insight into the evolution of vertebrate freeze tolerance. 


\section{TABLES}

Table 1 Seasonal variation in plasma membrane phospholipid classes and cholesterol in liver and brain tissue of Rana sylvatica from Ohio.

\begin{tabular}{|c|c|c|c|c|c|}
\hline & Summer & Fall & Winter & $F$ & $P$ \\
\hline \multicolumn{6}{|l|}{ Liver } \\
\hline $\mathrm{PC}$ & $43.3 \pm 0.6^{\mathrm{a}}$ & $37.7 \pm 0.7^{b}$ & $37.3 \pm 0.5^{\mathrm{b}}$ & 31.0 & $<0.0001$ \\
\hline $\mathrm{PE}$ & $35.5 \pm 0.5^{\mathrm{a}}$ & $38.2 \pm 0.4^{\mathrm{b}}$ & $38.0 \pm 0.6^{\mathrm{b}}$ & 7.9 & 0.003 \\
\hline PI & $8.1 \pm 0.9$ & $9.3 \pm 0.4$ & $10.2 \pm 0.2$ & 2.7 & 0.091 \\
\hline PS & $11.0 \pm 0.7$ & $11.8 \pm 0.5$ & $11.7 \pm 0.6$ & 0.6 & 0.564 \\
\hline $\mathrm{SM}$ & $1.9 \pm 0.2^{\mathrm{a}}$ & $2.7 \pm 0.1^{b}$ & $2.5 \pm 0.2^{\mathrm{ab}}$ & 5.7 & 0.012 \\
\hline LPC & $0.2 \pm 0.04$ & $0.3 \pm 0.1$ & $0.4 \pm 0.1$ & 2.1 & 0.148 \\
\hline $\mathrm{CH}$ & $16.0 \pm 1.1$ & $16.6 \pm 1.0$ & $15.6 \pm 1.2$ & 0.2 & 0.792 \\
\hline $\mathrm{CH} / \mathrm{PL}$ & $0.21 \pm 0.02$ & $0.22 \pm 0.02$ & $0.20 \pm 0.02$ & 0.2 & 0.846 \\
\hline $\mathrm{PC} / \mathrm{PE}$ & $1.22 \pm 0.03^{\mathrm{a}}$ & $0.99 \pm 0.02^{\mathrm{b}}$ & $0.98 \pm 0.02^{b}$ & 31.0 & $<0.0001$ \\
\hline $\mathrm{PC} / \mathrm{PI}$ & $5.75 \pm 0.65^{\mathrm{a}}$ & $4.12 \pm 0.26^{\mathrm{b}}$ & $3.74 \pm 0.24^{b}$ & 6.2 & 0.009 \\
\hline $\mathrm{PC} /(\mathrm{PE}+\mathrm{SM})$ & $1.16 \pm 0.03^{\mathrm{a}}$ & $0.92 \pm 0.02^{\mathrm{b}}$ & $0.92 \pm 0.01^{b}$ & 40.1 & $<0.0001$ \\
\hline \multicolumn{6}{|l|}{ Brain } \\
\hline $\mathrm{PC}$ & $41.6 \pm 1.3$ & $43.4 \pm 1.0$ & $42.0 \pm 0.8$ & 0.5 & 0.633 \\
\hline $\mathrm{PE}$ & $47.9 \pm 1.7$ & $46.6 \pm 1.1$ & $49.1 \pm 0.5^{\dagger}$ & 1.0 & 0.406 \\
\hline PI & $3.9 \pm 0.5$ & $4.5 \pm 0.6$ & $3.7 \pm 0.2$ & 0.6 & 0.554 \\
\hline PS & $5.7 \pm 0.3$ & $4.5 \pm 0.3$ & $5.3 \pm 0.5$ & 2.5 & 0.114 \\
\hline SM & $0.8 \pm 0.1$ & $0.9 \pm 0.2$ & $1.0 \pm 0.1$ & 0.4 & 0.703 \\
\hline LPC & $0.1 \pm 0.03$ & $0.1 \pm 0.1$ & $0.1 \pm 0.1$ & $2.1^{\ddagger}$ & 0.354 \\
\hline $\mathrm{CH}$ & $26.0 \pm 0.9$ & $27.8 \pm 1.3$ & $24.4 \pm 1.2$ & 2.2 & 0.136 \\
\hline $\mathrm{CH} / \mathrm{PL}$ & $0.37 \pm 0.02$ & $0.43 \pm 0.03$ & $0.34 \pm 0.02$ & 3.0 & 0.073 \\
\hline $\mathrm{PC} / \mathrm{PE}$ & $0.88 \pm 0.06$ & $0.94 \pm 0.04$ & $0.83 \pm 0.02$ & 1.4 & 0.276 \\
\hline $\mathrm{PC} / \mathrm{PI}$ & $11.85 \pm 1.59$ & $11.05 \pm 2.05$ & $10.69 \pm 0.30$ & 0.1 & 0.871 \\
\hline $\mathrm{PC} /(\mathrm{PE}+\mathrm{SM})$ & $0.87 \pm 0.05$ & $0.92 \pm 0.04$ & $0.81 \pm 0.02^{\dagger}$ & 1.4 & 0.264 \\
\hline
\end{tabular}

$P C$ phosphatidylcholine, $P E$ phosphatidylethanolamine, $P I$ phosphatidylinositol, $P S$

phosphatidylserine, SM sphingomyelin, $L P C$ lysophosphatidylcholine, $C H$ cholesterol, $C H / P L$ 
cholesterol to total phospholipid ratio, $P C / P E$ phosphatidylcholine to phosphatidylethanolamine ratio, $P C / P I$ phosphatidylcholine to phosphatidylinositol ratio, $P C /(P E+S M)$ ratio of phosphatidylcholine to phosphatidylethanolamine and sphingomyelin. Values are reported as mean $\pm \operatorname{SEM}$ with $n=7$, unless denoted ${ }^{\dagger}$, where $n=6$. Values for phospholipid classes are percentages of total phospholipids and values for $\mathrm{CH}$ are percentages of total lipids.

ANOVA/Bonferroni or Kruskal-Wallis $\left(H\right.$ value denoted $\left.^{\ddagger}\right)$ was used to compare groups within each population. In cases where means were significant $(P<0.05), P$ values are bolded and dissimilar letters distinguish groups. 
Table 2 Seasonal variation in plasma membrane phospholipid classes and cholesterol in liver and brain tissue of $R$. sylvatica from Alaska.

\begin{tabular}{|c|c|c|c|c|c|}
\hline & Summer & Fall & Winter & $F$ & $P$ \\
\hline \multicolumn{6}{|l|}{ Liver } \\
\hline $\mathrm{PC}$ & $39.2 \pm 0.6$ & $39.2 \pm 1.0$ & $41.9 \pm 1.0$ & 3.1 & 0.069 \\
\hline PE & $36.0 \pm 0.7^{\mathrm{a}}$ & $38.3 \pm 0.8^{\mathrm{ab}}$ & $38.5 \pm 0.3^{\mathrm{b}}$ & 4.9 & 0.019 \\
\hline PI & $7.8 \pm 0.5$ & $7.4 \pm 0.7$ & $6.5 \pm 0.5$ & 1.3 & 0.287 \\
\hline PS & $13.9 \pm 0.6^{\mathrm{a}}$ & $12.4 \pm 0.7^{\mathrm{ab}}$ & $10.3 \pm 0.5^{\mathrm{b}}$ & 9.6 & 0.001 \\
\hline SM & $3.0 \pm 0.2$ & $2.7 \pm 0.3$ & $2.5 \pm 0.3$ & 0.9 & 0.420 \\
\hline LPC & $0.2 \pm 0.1$ & $0.1 \pm 0.03$ & $0.3 \pm 0.1$ & 0.7 & 0.530 \\
\hline $\mathrm{CH}$ & $12.7 \pm 1.0$ & $13.8 \pm 1.7$ & $13.8 \pm 1.7$ & 0.1 & 0.865 \\
\hline $\mathrm{CH} / \mathrm{PL}$ & $0.15 \pm 0.01$ & $0.17 \pm 0.02$ & $0.18 \pm 0.02$ & 0.3 & 0.759 \\
\hline $\mathrm{PC} / \mathrm{PE}$ & $1.09 \pm 0.03$ & $1.03 \pm 0.03$ & $1.09 \pm 0.03$ & 1.6 & 0.231 \\
\hline $\mathrm{PC} / \mathrm{PI}$ & $5.18 \pm 0.33$ & $5.63 \pm 0.61$ & $6.69 \pm 0.59$ & 2.2 & 0.141 \\
\hline $\mathrm{PC} /(\mathrm{PE}+\mathrm{SM})$ & $1.01 \pm 0.02$ & $0.96 \pm 0.03$ & $1.03 \pm 0.03$ & 1.3 & 0.293 \\
\hline \multicolumn{6}{|l|}{ Brain } \\
\hline $\mathrm{PC}$ & $42.2 \pm 0.9$ & $41.1 \pm 0.8^{\dagger}$ & $44.7 \pm 2.0$ & 1.7 & 0.210 \\
\hline PE & $47.3 \pm 0.6$ & $48.5 \pm 0.9^{\dagger}$ & $45.6 \pm 1.5$ & 1.7 & 0.213 \\
\hline PI & $4.2 \pm 0.7$ & $4.2 \pm 0.7$ & $3.9 \pm 0.4$ & 0.1 & 0.932 \\
\hline PS & $5.4 \pm 0.7$ & $4.6 \pm 0.5$ & $4.8 \pm 0.7$ & 0.4 & 0.650 \\
\hline SM & $0.8 \pm 0.1$ & $0.9 \pm 0.1$ & $0.9 \pm 0.2$ & 0.3 & 0.763 \\
\hline LPC & $0.1 \pm 0.02$ & $0.1 \pm 0.04$ & $0.1 \pm 0.04$ & 0.3 & 0.724 \\
\hline $\mathrm{CH}$ & $24.7 \pm 2.2$ & $26.0 \pm 1.9$ & $27.7 \pm 1.7$ & 0.6 & 0.538 \\
\hline $\mathrm{CH} / \mathrm{PL}$ & $0.36 \pm 0.04$ & $0.40 \pm 0.05$ & $0.43 \pm 0.04$ & 0.6 & 0.542 \\
\hline $\mathrm{PC} / \mathrm{PE}$ & $0.89 \pm 0.03$ & $0.85 \pm 0.03$ & $1.00 \pm 0.08$ & 2.0 & 0.164 \\
\hline $\mathrm{PC} / \mathrm{PI}$ & $12.04 \pm 2.29$ & $9.64 \pm 0.97$ & $12.99 \pm 2.39$ & 0.7 & 0.532 \\
\hline $\mathrm{PC} /(\mathrm{PE}+\mathrm{SM})$ & $0.88 \pm 0.03$ & $0.84 \pm 0.03^{\dagger}$ & $0.97 \pm 0.07$ & 2.0 & 0.171 \\
\hline
\end{tabular}

Abbreviations, sample sizes, symbology, and treatment of data as in Table 1. 
Table 3 Phospholipid classes and cholesterol in liver and brain tissue of winter-acclimatized Ohioan $R$. sylvatica acclimated to different temperatures.

\begin{tabular}{|c|c|c|c|c|c|}
\hline & $10^{\circ} \mathrm{C}$ & $4^{\circ} \mathrm{C}$ & $0^{\circ} \mathrm{C}$ & $F$ & $P$ \\
\hline \multicolumn{6}{|l|}{ Liver } \\
\hline PC & $40.1 \pm 1.0$ & $38.9 \pm 1.4$ & $37.6 \pm 1.0$ & 1.3 & 0.298 \\
\hline PE & $37.3 \pm 0.3^{\mathrm{a}}$ & $39.9 \pm 0.8^{\mathrm{b}}$ & $41.1 \pm 0.6^{\mathrm{b}}$ & 11.0 & 0.002 \\
\hline PI & $9.5 \pm 0.8$ & $9.0 \pm 1.0$ & $8.4 \pm 0.6$ & 0.4 & 0.655 \\
\hline PS & $10.8 \pm 0.6$ & $9.9 \pm 0.7$ & $11.0 \pm 0.9$ & 0.6 & 0.585 \\
\hline SM & $2.2 \pm 0.1$ & $1.9 \pm 0.1$ & $1.8 \pm 0.1$ & 1.9 & 0.188 \\
\hline LPC & $0.2 \pm 0.1$ & $0.3 \pm 0.1$ & $0.2 \pm 0.1$ & 0.6 & 0.581 \\
\hline $\mathrm{CH}$ & $15.5 \pm 1.5$ & $17.4 \pm 1.5$ & $16.9 \pm 0.8$ & 0.5 & 0.591 \\
\hline $\mathrm{CH} / \mathrm{PL}$ & $0.20 \pm 0.02$ & $0.23 \pm 0.03$ & $0.22 \pm 0.01$ & 0.6 & 0.577 \\
\hline $\mathrm{PC} / \mathrm{PE}$ & $1.08 \pm 0.03^{\mathrm{a}}$ & $0.98 \pm 0.05^{\mathrm{ab}}$ & $0.91 \pm 0.03^{b}$ & 4.5 & 0.036 \\
\hline $\mathrm{PC} / \mathrm{PI}$ & $4.37 \pm 0.43$ & $4.64 \pm 0.74$ & $4.58 \pm 0.36$ & 0.1 & 0.934 \\
\hline $\mathrm{PC} /(\mathrm{PE}+\mathrm{SM})$ & $1.02 \pm 0.03$ & $0.94 \pm 0.05$ & $0.88 \pm 0.03$ & 3.7 & 0.056 \\
\hline \multicolumn{6}{|l|}{ Brain } \\
\hline PC & $46.2 \pm 2.5$ & $46.1 \pm 1.2$ & $45.2 \pm 1.1$ & 0.1 & 0.911 \\
\hline $\mathrm{PE}$ & $43.0 \pm 2.0$ & $43.9 \pm 0.8$ & $43.9 \pm 0.8$ & 0.2 & 0.846 \\
\hline PI & $5.0 \pm 0.4$ & $5.1 \pm 0.6$ & $6.0 \pm 0.5$ & 1.0 & 0.383 \\
\hline PS & $5.0 \pm 0.5$ & $4.3 \pm 0.2$ & $4.0 \pm 0.3$ & 2.3 & 0.141 \\
\hline SM & $0.8 \pm 0.2$ & $0.6 \pm 0.1$ & $0.9 \pm 0.1$ & $4.9^{*}$ & 0.087 \\
\hline LPC & $0.1 \pm 0.01$ & $0.1 \pm 0.02$ & $0.1 \pm 0.02$ & 0.8 & 0.491 \\
\hline $\mathrm{CH}$ & $28.6 \pm 1.6^{\mathrm{a}}$ & $24.5 \pm 0.9^{\mathrm{ab}}$ & $23.1 \pm 1.3^{\mathrm{b}}$ & 5.0 & 0.026 \\
\hline $\mathrm{CH} / \mathrm{PL}$ & $0.43 \pm 0.04^{\mathrm{a}}$ & $0.35 \pm 0.01^{\mathrm{ab}}$ & $0.32 \pm 0.02^{\mathrm{b}}$ & 5.4 & 0.021 \\
\hline $\mathrm{PC} / \mathrm{PE}$ & $1.09 \pm 0.11$ & $1.05 \pm 0.04$ & $1.03 \pm 0.04$ & 0.2 & 0.836 \\
\hline $\mathrm{PC} / \mathrm{PI}$ & $9.60 \pm 1.25$ & $9.86 \pm 1.52$ & $7.82 \pm 0.70$ & 0.8 & 0.452 \\
\hline $\mathrm{PC} /(\mathrm{PE}+\mathrm{SM})$ & $1.08 \pm 0.11$ & $1.04 \pm 0.04$ & $1.01 \pm 0.04$ & 0.2 & 0.831 \\
\hline
\end{tabular}

Abbreviations and derivation of percentages as in Table 1. Values are reported as mean \pm SEM with $n=5$. ANOVA/Bonferroni or Kruskal-Wallis ( $H$ value denoted $\left.{ }^{\ddagger}\right)$ was used to compare groups. In cases where means were significant $(P<0.05), P$ values are bolded and dissimilar letters distinguish groups. 
Table 4 Phospholipid classes and cholesterol in liver and brain tissue of winter-acclimatized unfrozen, frozen $48 \mathrm{~h}$, and frozen $48 \mathrm{~h}$ and subsequently thawed $5 \mathrm{~d} R$. sylvatica from Ohio.

\begin{tabular}{|c|c|c|c|c|c|}
\hline & Unfrozen & Frozen & Thawed & $F$ & $P$ \\
\hline \multicolumn{6}{|l|}{ Liver } \\
\hline PC & $39.3 \pm 1.2$ & $38.0 \pm 1.4$ & $38.4 \pm 1.0$ & 0.3 & 0.721 \\
\hline PE & $40.1 \pm 0.6$ & $39.1 \pm 0.4$ & $39.6 \pm 0.6$ & 0.9 & 0.423 \\
\hline PI & $7.8 \pm 1.0$ & $9.3 \pm 0.8$ & $8.4 \pm 1.2$ & 0.5 & 0.595 \\
\hline PS & $11.0 \pm 0.4^{\dagger}$ & $10.9 \pm 0.7$ & $10.9 \pm 0.4$ & $<0.0001$ & 0.988 \\
\hline SM & $2.1 \pm 0.3$ & $2.6 \pm 0.2$ & $2.6 \pm 0.2$ & 1.4 & 0.286 \\
\hline LPC & $0.1 \pm 0.03^{\dagger}$ & $0.2 \pm 0.02$ & $0.2 \pm 0.03$ & 1.2 & 0.316 \\
\hline $\mathrm{CH}$ & $20.0 \pm 1.1$ & $16.5 \pm 0.6$ & $18.1 \pm 1.3$ & 2.7 & 0.095 \\
\hline $\mathrm{CH} / \mathrm{PL}$ & $0.28 \pm 0.02$ & $0.21 \pm 0.01$ & $0.24 \pm 0.02$ & 2.9 & 0.086 \\
\hline $\mathrm{PC} / \mathrm{PE}$ & $0.98 \pm 0.03$ & $0.97 \pm 0.04$ & $0.97 \pm 0.02$ & 0.03 & 0.970 \\
\hline PC/PI & $4.63 \pm 0.40$ & $4.30 \pm 0.49$ & $5.40 \pm 1.13$ & 0.6 & 0.581 \\
\hline $\mathrm{PC} /(\mathrm{PE}+\mathrm{SM})$ & $0.93 \pm 0.03$ & $0.91 \pm 0.05$ & $0.91 \pm 0.02$ & 0.1 & 0.875 \\
\hline \multicolumn{6}{|l|}{ Brain } \\
\hline PC & $38.4 \pm 1.3$ & $37.6 \pm 1.1$ & $40.5 \pm 0.8$ & 1.6 & 0.227 \\
\hline $\mathrm{PE}$ & $48.0 \pm 1.6$ & $49.6 \pm 0.5$ & $47.4 \pm 1.6$ & 0.6 & 0.544 \\
\hline PI & $5.5 \pm 0.9$ & $4.1 \pm 0.2^{\dagger}$ & $4.2 \pm 1.2$ & 0.7 & 0.504 \\
\hline PS & $7.6 \pm 0.9$ & $7.2 \pm 0.6$ & $7.0 \pm 0.7$ & 0.1 & 0.896 \\
\hline SM & $0.5 \pm 0.1$ & $0.6 \pm 0.02$ & $0.8 \pm 0.1$ & $5.2^{\ddagger}$ & 0.074 \\
\hline LPC & $0.1 \pm 0.03$ & $0.1 \pm 0.02$ & $0.1 \pm 0.03$ & $0.2^{\ddagger}$ & 0.904 \\
\hline $\mathrm{CH}$ & $28.9 \pm 1.9$ & $28.1 \pm 1.3$ & $27.5 \pm 1.5$ & 0.2 & 0.829 \\
\hline $\mathrm{CH} / \mathrm{PL}$ & $0.46 \pm 0.05$ & $0.43 \pm 0.03$ & $0.41 \pm 0.03$ & 0.4 & 0.668 \\
\hline $\mathrm{PC} / \mathrm{PE}$ & $0.81 \pm 0.05$ & $0.76 \pm 0.03$ & $0.86 \pm 0.04$ & 1.4 & 0.270 \\
\hline $\mathrm{PC} / \mathrm{PI}$ & $8.72 \pm 2.00$ & $8.47 \pm 1.07$ & $15.23 \pm 4.34$ & 1.9 & 0.184 \\
\hline $\mathrm{PC} /(\mathrm{PE}+\mathrm{SM})$ & $0.80 \pm 0.05$ & $0.75 \pm 0.03$ & $0.84 \pm 0.04$ & 1.4 & 0.287 \\
\hline
\end{tabular}

Abbreviations and derivation of percentages as in Table 1. Values are reported as mean \pm SEM with $n=7$ in the unfrozen group and $n=6$ in the frozen and thawed groups, unless denoted ${ }^{\dagger}$ where $n=$ group $n-1$. ANOVA or Kruskal-Wallis $\left(H\right.$ values denoted $\left.{ }^{\ddagger}\right)$ was used to compare groups. 


\section{FIGURE CAPTIONS}

Figure 1 Climatic variability as represented by the monthly average maximum and minimum air temperatures at locales near the source of the Ohioan and Alaskan frogs used in the study. Values presented for each month $(\bullet$, Ohio; ○, Alaska) are averages of all daily values recorded at field stations in the three years (2010-2012) during which the study was conducted. Maximum and minimum temperatures at each locale are represented by the upper and lower lines (-, Ohio; - -, Alaska), respectively. Data were compiled from NOAA records for Portsmouth, $\mathrm{OH}$, and Fairbanks, AK.

Figure 2 Variation in lipid composition of liver membranes from Ohioan and Alaskan frogs sampled in three seasons. Symbols represent the mean ( \pm SEM, $n=7)$ percentage of total phospholipids represented by phosphatidylcholine, PC; phosphatidylethanolamine, PE; phosphatidylinositol, PI; phosphatidylserine, PS; sphingomyelin, SM; and lysophosphatidylcholine, LPC; or the mean ( \pm SEM, $n=7)$ percentage of total lipids represented by cholesterol, $\mathrm{CH}$. Asterisks indicate that the pair of means within each season differed significantly (Bonferroni, $P<0.05$ ). For $\mathrm{CH}$, there were no statistical differences between populations in any season, although the overall population effect was significant (ANOVA: $F_{1,36}$ $=6.6, P=0.015)$.

Figure 3 Variation in lipid ratios within liver membranes from Ohioan and Alaskan frogs sampled in three seasons. Symbols represent mean $( \pm$ SEM, $n=7)$ ratios for phosphatidylcholine to phosphatidylethanolamine, PC/PE; phosphatidylcholine to phosphatidylinositol, PC/PI; phosphatidylcholine to the sum of phosphatidylethanolamine and sphingomyelin, $\mathrm{PC} /(\mathrm{PE}+\mathrm{SM})$; and cholesterol to total phospholipids, $\mathrm{CH} / \mathrm{PL}$. Asterisks indicate that the pair of means within each season differed significantly (Bonferroni, $P<0.05$ ). For $\mathrm{CH} / \mathrm{PL}$, there were no statistical differences between populations in any season, although the overall population effect was significant (ANOVA: $\left.F_{1,36}=6.6, P=0.015\right)$. 


\section{FIGURES}

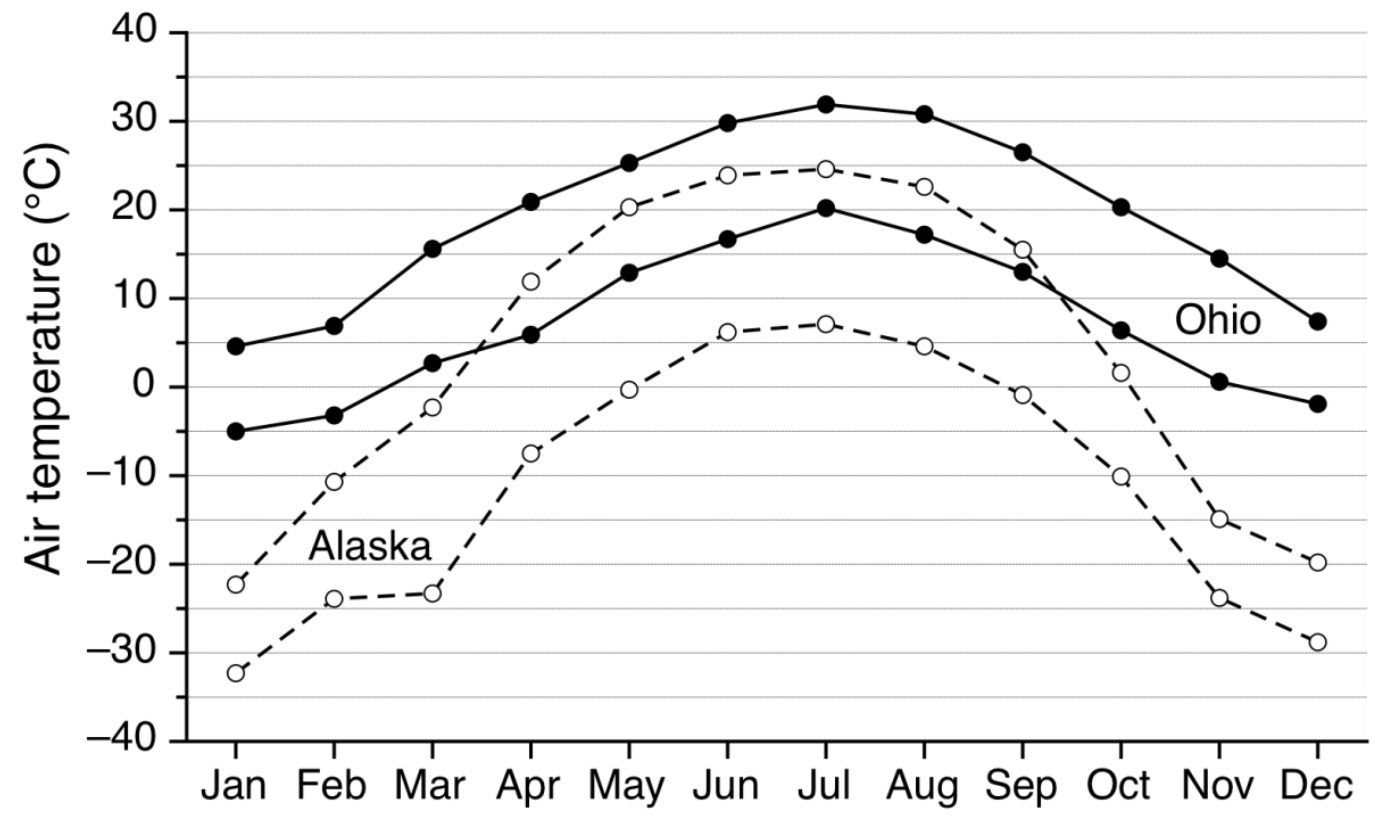

Figure 1 

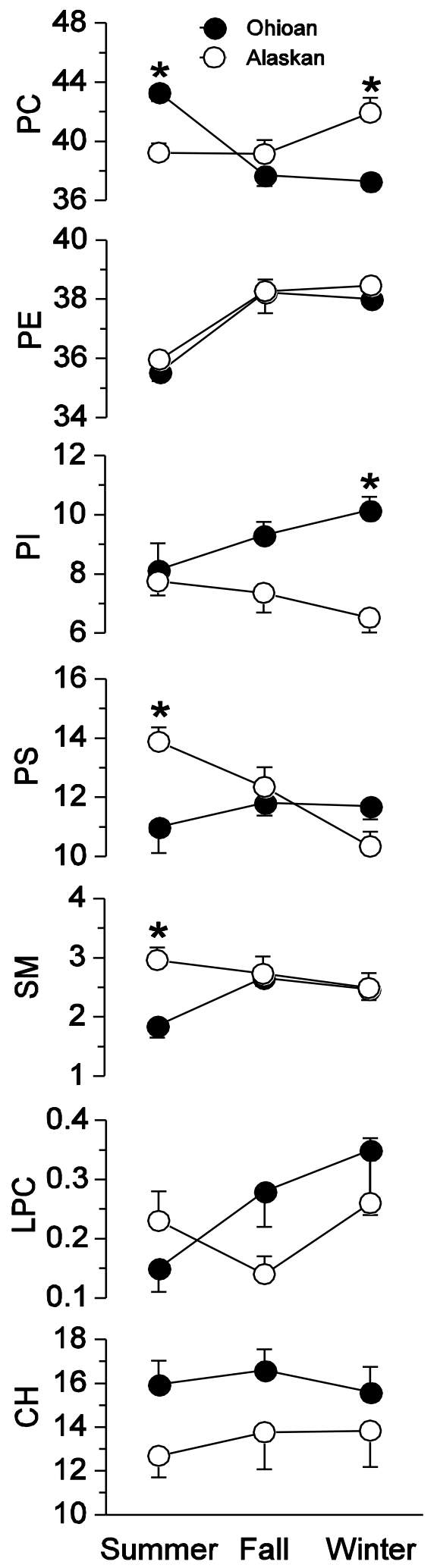

Figure 2 

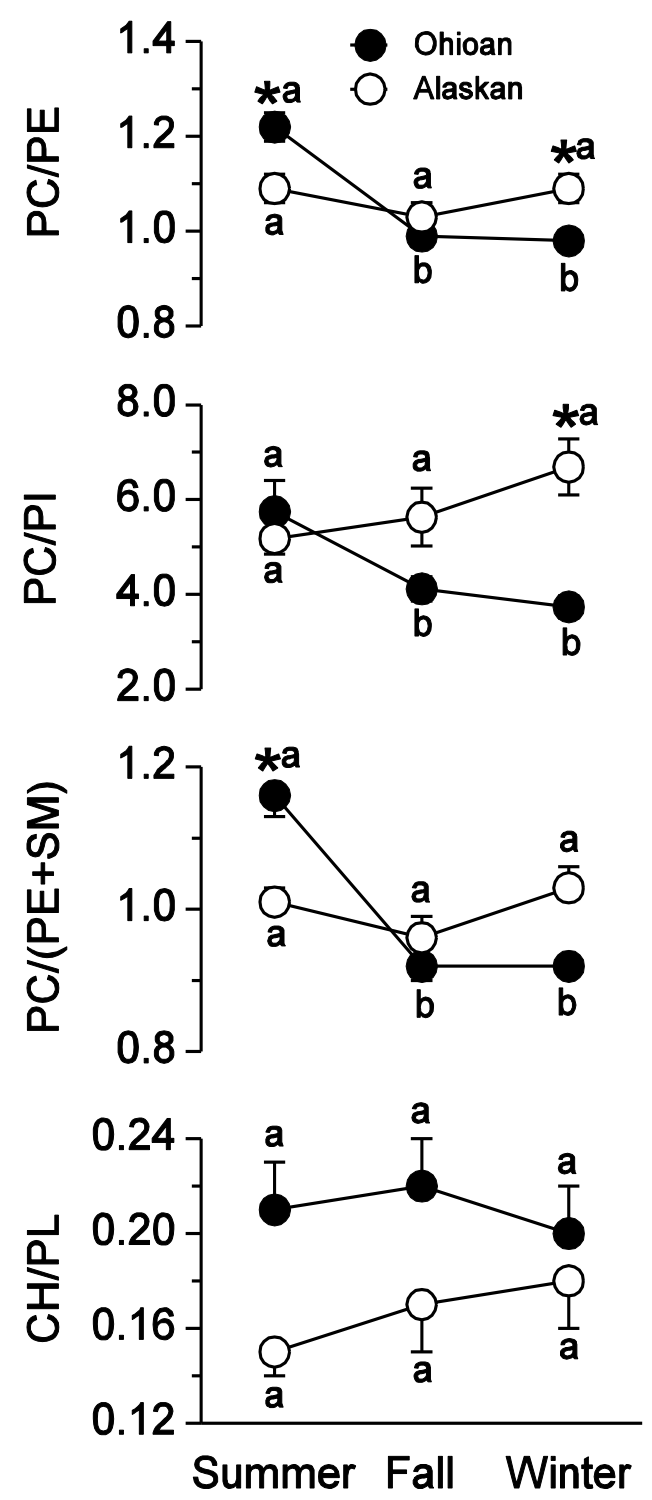

Figure 3 


\section{REFERENCES}

Behan-Martin MK, Jones GR, Bowler K, Cossins AR (1993) A near perfect temperature adaptation of bilayer order in vertebrate brain membranes. Biochim Biophys Acta 1151:216-222

Beney L, Gervais P (2001) Influence of the fluidity of the membrane on the response of microorganisms to environmental stresses. Appl Microbiol Biotechnol 57:34-42

Berner NJ, Else PL, Hulbert AJ, Mantle BL, Cramp RL, Franklin CE (2009) Metabolic depression during aestivation does not involve remodeling of membrane fatty acids in two Australian frogs. J Comp Physiol B 179:857-866

Bitman J, Wood DL (1982) An improved copper reagent for quantitative densitometric thin-layer chromatography of lipids. J Liq Chromatogr 5:1155-1162

Boggs JM, Stamp D, Hughes DW, Deber CM (1981) Influence of ether linkage on the lamellar to hexagonal phase transition of ethanolamine phospholipids. Biochemistry 20:57285735

Bradford MM (1976) A rapid and sensitive method for the quantitation of microgram quantities of protein utilizing the principle of protein-dye binding. Anal Biochem 72:248-254

Brooks S, Clark GT, Wright SM, Trueman RJ, Postle AD, Cossins AR, Maclean NM (2002) Electrospray ionisation mass spectrometric analysis of lipid restructuring in the carp (Cyrinus carpio L.) during cold acclimation. J Exp Biol 205:3989-3997

Bullock TH (1955) Compensation for temperature in the metabolism and activity of poikilotherms. Biol Rev Camb Philos Soc 30:311-342

Carey C, Hazel JR (1989) Diurnal variation in membrane lipid composition of Sonoran desert teleosts. J Exp Biol 147:375-391

Chapman D (1975) Phase transitions and fluidity characteristics of lipids and cell membranes. Q Rev Biophys 8:185-235

Collins SD, Allenspach AL, Lee RE (1997) Ultrastructural effects of lethal freezing on brain, muscle and Malpighian tubules from freeze-tolerant larvae of the gall fly, Eurosta solidaginis. J Insect Physiol 43:39-45

Cossins AR, Prosser CL (1978) Evolutionary adaptation of membranes to temperature. Proc Natl Acad Sci USA 75:2040-2043 
Costa-Balogh FO, Wennerström H, Wadsö L, Sparr E (2006) How small polar molecules protect membrane systems against osmotic stress: the urea-water-phospholipid system. J Phys Chem B 110:23845-23852

Costanzo JP, do Amaral MCF, Rosendale AJ, Lee RE (2013) Hibernation physiology, freezing adaptation, and extreme freeze tolerance in a northern population of wood frog. J Exp Biol 216:3461-3473

Costanzo JP, Lee RE (2013) Avoidance and tolerance of freezing in ectothermic vertebrates. J Exp Biol 216:1961-1967

Crockett EL (1998) Cholesterol function in plasma membranes from ectotherms: membranespecific roles in adaptation to temperature. Am Zool 38:291-304

Crowe JH, Crowe LM (1986) Hydration-dependent phase transitions and permeability properties of biological membranes. In: Leopold AC (ed) Membranes, metabolism, and dry organisms. Comstock Publishing Associates, Ithaca, pp 210-230

Crowe JH, Crowe LM, Carpenter JF (1987) Stabilization of dry phospholipid bilayers and proteins by sugars. Biochem J 242:1-10

Cuculescu M, Hyde D, Bowler K (1995) Temperature acclimation of marine crabs: changes in plasma membrane fluidity and lipid composition. J Therm Biol 20:207-222

Cuzner ML, Davison AN, Gregson NA (1965) The chemical composition of vertebrate myelin and microsomes. J Neurochem 12:469-481

Drobnis EZ, Crowe LM, Berger T, Anchordoguy TJ, Overstreet JW, Crowe JH (1993) Cold shock damage is due to lipid phase transitions in cell membranes: a demonstration using sperm as a model. J Exp Zool 265:432-437

Fajardo VA, McMeekin L, LeBlanc PJ (2011) Influence of phospholipid species on membrane fluidity: a meta-analysis for a novel phospholipid fluidity index. J Membr Biol 244:97103

Finegold L (1996) Molecular and biophysical aspects of adaptation of life to temperatures below the freezing point. Adv Space Res 18:(12)87-(12)95

Graham JM (1993) The identification of subcellular fractions from mammalian cells. In: Graham JM, Higgins JA (eds) Methods in molecular biology, vol 19. Biomembrane protocols: I. Isolation and analysis. Humana Press, Totowa, pp 1-28 
Hassett RP, Crockett EL (2009) Habitat temperature is an important determinant of cholesterol contents in copepods. J Exp Biol 212: 71-77

Hazel JR (1988) Homeoviscous adaptation in animal cell membranes. In: Aloia RC, Curtin CC, Gordon LM (eds) Advances in membrane fluidity - physiological regulation of membrane fluidity. Liss, New York, pp 149-188

Hazel JR (1989) Cold adaptation in ectotherms: regulation of membrane function and cellular metabolism. In: Wang LCH (ed) Advances in comparative and environmental physiology 4: animal adaptation to cold. Springer-Verlag, New York, pp 1-50

Hazel JR (1995) Thermal adaptation in biological membranes: is homeoviscous adaptation the explanation? Annu Rev Physiol 57:19-42

Hrycay EG, O’Brien PJ (1974) Microsomal electron transport: II. Reduced nicotinamide adenine dinucleotide-cytochrome $\mathrm{b}_{5}$ reductase and cytochrome $\mathrm{P}-450$ as electron carriers in microsomal NADH-peroxidase activity. Arch Biochem Biophys 160:230-245

Jendrasiak GL (1996) The hydration of phospholipids and its biological significance. J Nutr Biochem 7:599-609

Koštál V (2010) Cell structural modifications in insects at low temperatures. In: Denlinger DL, Lee RE (eds) Low temperature biology of insects. Cambridge University Press, Cambridge, pp 116-140

Lee AG (1977) Lipid phase transitions and phase diagrams: II. Mixtures involving lipids. Biochim Biophys Acta 472:285-344

Lee RF (1974) Lipid composition of the copepod Calanus hyperboreas from the Arctic Ocean: changes with depth and season. Mar Biol 26:313-318

Leventis PA, Grinstein S (2010) The distribution and function of phosphatidylserine in cellular membranes. Annu Rev Biophys 39:407-427

Levitt J (1980) Physiological ecology: a series of monographs, texts, and treatises: I. Chilling, freezing and high temperature stresses. Academic Press, New York

Martof BS, Humphries RL (1959) Geographic variation in the wood frog Rana sylvatica. Am Midl Nat 61:350-389

Muir TJ, Costanzo JP, Lee RE (2010) Brief chilling to subzero temperature increases cold hardiness in the hatchling painted turtle (Chrysemys picta). Physiol Biochem Zool $83: 174-181$ 
Persson A, Jergil B (1992) Purification of plasma membranes by aqueous two-phase affinity partitioning. Anal Biochem 2041:31-136

Pruitt NL (1988) Membrane lipid composition and overwintering strategy in thermally acclimated crayfish. Am J Physiol 254:R870-R876

Pruitt NL, Lu C (2008) Seasonal changes in phospholipid class and class-specific fatty acid composition associated with the onset of freeze tolerance in third-instar larvae of Eurosta solidaginis. Physiol Biochem Zool 81:226-234

Quinn PJ (1985) A lipid-phase separation model of low-temperature damage to biological membranes. Cryobiology 22:128-146

Radin NS, Deshmukh GD, Selvam R, Hospattankar AV (1982) Determination of glucocerebroside, sphingomyelin, free fatty acid and total lipid by thin layer chromatography and charring-scintillation quenching. Biochim Biophys Acta 713:474478

Robertson JC, Hazel JR (1996) Membrane constraints to physiological function at different temperatures: does cholesterol stabilize membranes at elevated temperatures? In: Wood CM, McDonald DG (eds) Global warming: implications for freshwater and marine fish. Cambridge University Press, Cambridge, pp 25-49

Rouser G, Simon G, Kritchevsky G (1969) Species variations in phospholipid class distribution of organs: I. Kidney, liver and spleen. Lipids 4:599-606

Ruiz JI, Ochoa B (1997) Quantification in the subnanomolar range of phospholipids and neutral lipids by monodimensional thin-layer chromatography and image analysis. J Lipid Res 38:1482-1489

Scapin S, Baldini P, Luly P (1990) Phospholipid and fatty acid composition of frog (Rana esculenta) liver - a circannual study. Lipids 25:443-449

Schindler J, Lewandrowski U, Sickmann A, Friauf E, Nothwang HG (2006) Proteomic analysis of brain plasma membranes isolated by affinity two-phase partitioning. Mol Cell Proteomics 5:390-400

Schmitz G, Assmann G, Bowyer DE (1984) Quantitative densitometric method for the rapid separation and quantitation of the major tissue and lipoprotein lipids by high-performance thin-layer chromatography: I. Sample preparation, chromatography, and densitometry. J Chromatogr 307:65-79 
Schuh TJ (2002) An introduction to lipid analysis in the cell biology laboratory. Am Biol Teach 64:122-129

Siakotos AN, Rouser G, Fleischer S (1969) Phospholipid composition of human, bovine and frog myelin isolated on a large scale from brain and spinal cord. Lipids 4:239-242

Sikorska E, Kacperska-Palacz A (1980) Frost-induced phospholipid changes in cold-acclimated and non-acclimated rape leaves. Physiol Plant 48:201-206

Slotte, JP (2013) Biological functions of sphingomyelins. Prog Lipid Res 52:424-437

Sørensen PG (1993) Changes of the composition of phospholipids, fatty acids and cholesterol from the erythrocyte plasma membrane from flounders (Platichthys flesus L.) which were acclimated to high and low temperatures in aquaria. Comp Biochem Physiol B 106:907912

Stanley-Samuelson DW, Rapport EW, Dadd RH (1985) Effects of dietary polyunsaturated fatty acids on tissue monosaturate and saturate proportions in two insect species. Comp Biochem Physiol B 81:749-754

Steponkus PL (1984) Role of the plasma membrane in freezing injury and cold acclimation. Annu Rev Plant Physiol 35:543-584

Storey KB, Storey JM (2013) Molecular biology of freezing tolerance. Compr Physiol 3:12831308

Tomčala A, Tollarová M, Overgaard J, Šimek P, Koštál V (2006) Seasonal acquisition of chill tolerance and restructuring of membrane glycerophospholipids in an overwintering insect: triggering by low temperature, desiccation and diapause progression. J Exp Biol 209:4102-4114

van Dooremalen C, Suring W, Ellers J (2011) Fatty acid composition and extreme temperature tolerance following exposure to fluctuating temperatures in a soil arthropod. J Insect Physiol 57:1267-1273

Welti R, Li W, Li M, Sang Y, Biesiada H, Zhou HE, Rajashekar CB, Williams TD, Wang X (2002) Profiling membrane lipids in plant stress responses: role of phospholipase D $\alpha$ in freezing-induced lipid changes in Arabidopsis. J Biol Chem 277:31994-32002

Williams EE, Hazel JR (1995) Restructuring of plasma membrane phospholipids in isolating hepatocytes of rainbow trout during brief in vitro cold exposure. J Comp Physiol B 164:600-608 
Wodtke E (1978) Lipid adaptation in liver mitochondrial membranes of carp acclimated to different environmental temperatures: phospholipid composition fatty acid pattern and cholesterol content. Biochim Biophys Acta 529:280-291

Yeagle PL (1985) Cholesterol and the cell membrane. Biochim Biophys Acta 822:267-287

Zehmer JK, Hazel JR (2005) Thermally induced changes in lipid composition of raft and nonraft regions of hepatocyte plasma membranes of rainbow trout. J Exp Biol 208:42834290 